\title{
German Bight residual current variability on a daily basis: principal components of multi-decadal barotropic simulations
}

\author{
Ulrich Callies $^{1}$ (D) $\cdot$ Lidia Gaslikova $^{1} \cdot$ Hartmut Kapitza $^{1} \cdot$ Mirco Scharfe $^{2}$
}

Received: 15 February 2016 / Accepted: 12 August 2016 / Published online: 19 August 2016

(C) The Author(s) 2016. This article is published with open access at Springerlink.com

\begin{abstract}
Time variability of Eulerian residual currents in the German Bight (North Sea) is studied drawing on existing multi-decadal 2D barotropic simulations $(1.6 \mathrm{~km}$ resolution) for the period Jan. 1958-Aug. 2015. Residual currents are calculated as $25 \mathrm{~h}$ means of velocity fields stored every hour. Principal component analysis (PCA) reveals that daily variations of these residual currents can be reasonably well represented in terms of only $2-3$ degrees of freedom, partly linked to wind directions. The daily data refine monthly data already used in the past. Unlike existing classifications based on subjective assessment, numerical principal components (PCs) provide measures of strength and can directly be incorporated into more comprehensive statistical data analyses. Daily resolution in particular fits the time schedule of data sampled at the German Bight long-term monitoring station at Helgoland Roads. An example demonstrates the use of PCs and corresponding empirical orthogonal functions (EOFs) for the interpretation of short-term variations of these local observations. On the other hand, monthly averaging of the daily PCs enables to link up with previous studies on longer timescales.
\end{abstract}

Responsible guest editor: C. Winter

Ulrich Callies

ulrich.callies@hzg.de

1 Helmholtz-Zentrum Geesthacht, Institute of Coastal Research, Max-Planck-Str. 1, 21502 Geesthacht, Germany

2 Biologische Anstalt Helgoland, Helmholtz-Centre for Polar and Marine Research, Alfred-Wegener-Institute, P.O. Box 180, 27483 Helgoland, Germany

\section{Introduction}

The North Sea is a shallow shelf sea in northwest Europe. A summary of its physics can be found in Sündermann and Pohlmann (2011), for instance. To the north the North Sea adjoins the north-eastern Atlantic (cf. connections via the Fair Island Current and Norwegian Trench), and in the south it connects to the Atlantic through the English Channel. Substantial amounts of brackish water are supplied through a connection with the Baltic Sea. Atlantic tidal waves trigger tides in the North Sea as co-oscillations. The German Bight is the shallow south-eastern part of the North Sea, where strong mixing processes caused by tidal currents and wind forcing counteract thermohaline stratification. Variations of the general circulation pattern in the German Bight and the whole North Sea are mainly controlled by variable atmospheric conditions (e.g. Backhaus 1989). Frequent westerly winds induce a mean cyclonic circulation. However, this pattern of transport is often disturbed and even reverses for longer periods particularly in summer.

The Federal Maritime and Hydrographic Agency (BSH) in Germany provides a classification of daily circulation patterns based on the uppermost $8 \mathrm{~m}$ of the hydrodynamic model BSHcmod (http://www.bsh. de/de/Meeresdaten/Beobachtungen/Zirkulationskalender Deutsche_Bucht/index.jsp) since 1997. These data were derived as a by-product of operational simulations so that data homogeneity, an issue of importance in all studies searching for trends or regime shifts, can be impaired by model updates. Homogeneous long-term reconstructions of environmental conditions are nowadays available from climate studies. The present analysis is based on barotropic North Sea simulations covering the period Jan. 1958-Aug. 2015, freely accessible at the coastDat-2 data base (see Gaslikova and Weisse 2013). 
Unlike mere (possibly subjective) classifications, principal components (PCs) analyzed statistically provide numerical measures of anomaly strengths and can hence easily be integrated into more comprehensive statistical analyses of monitoring data. In a recent study, Mathis et al. (2015) used principal component analysis (PCA) for a description of the variability of the vertically averaged North Sea general circulation. In their study the North Sea was embedded in the context of the greater northwest European shelf encompassing also the Baltic Sea. Referring to mean summer (June to August) and winter (December to February) conditions, Mathis et al. (2015) focussed on inter-annual variations during the years 1961-2000. A PCA of North Sea volume fluxes of 1962-2004 reported by Emeis et al. (2014) was based on monthly mean fields. Kauker and von Storch (2000) performed PCA for daily surface velocity stream function data from the winters (December to February) of 1979-1993, referring also to the whole North Sea. Stockmann et al. (2010), Scharfe (2013) and Callies and Scharfe (2015) focussed on the German Bight area, but 2D residual currents for 1958-2003 that they subjected to PCA were again defined on a monthly basis.

On an inter-annual timescale, the latter three studies identified substantial correlations between marine residual currents and observations at Helgoland Roads (cf. Fig. 1), where some of the longest time series monitored in the German Bight are available on a workday basis (Wiltshire et al. 2010). Interpretation of these data much benefits from resolving atmospheric variability and its marine responses on adequately short timescales. Lucas et al. (2016) provide an example of how the interpretation of measurements from a field study at Helgoland could be consolidated by analysing changes of water advection during the observational period.

The present study was conducted in close connection with WIMO, a German scientific project carried out by an interdisciplinary research consortium addressing various European and German regulations to assess the state of the marine environment in the German Bight (for overviews, see Winter et al. 2014; Winter et al., Introduction article for this special issue). One key issue of long-term ecosystem monitoring programs is to identify possible trends or regime shifts, either climatic or anthropogenic, against the background of natural variability (e.g. Schlüter et al. 2008). As both trends and variability much depend on a changing environment, identification of main drivers is an important issue (Wiltshire et al. 2015). Explicit discussions of a marine ecosystem's response to variable physical forcing can be found in Crise et al. (1999); Skogen and Moll (2000); Stenseth et al. (2005) and Parmesan et al. (2011), for instance.

Generally, hydrodynamic modelling can help gain better understanding of the dynamics of marine populations, communities and ecosystems (e.g. Robins et al. 2013; Daewel et al. 2015). The present paper focuses on the specific aspect of marine transport depending on variable atmospheric forcing. Oliver et al. (2015) proposed the use of multi-decadal meteorological reanalyses for a reconstruction of variations of larval connectivity patterns on the US Pacific coast. Wind-driven currents were also found to impact larval settlement rates at Helgoland (Giménez and Dick 2007). Model simulations are also useful for a better interpretation of environmental data collected during large field campaigns (e.g. Pohlmann et al. 1999). However, maintaining and running sophisticated models is a major task in itself, so that the scientific community tends to split into observers and modellers. What is more, from an observer's perspective often the outputs from even sophisticated models do not appear as direct counterparts of observations. Daewel and Schrum (2013) attributed some deficiencies of a 61 year North and Baltic Sea hindcast, recognized along the North Sea coastal zone, to the model's lack of a proper representation of tidal flats. This may be seen as an instance of spatial scale mismatch, a common problem in the comparison between field data and gridded model simulations. It raises the question of which specific aspects of model simulations can really support the interpretation of field observations. How much aggregation and possibly also simplification of model output is adequate for this purpose?

The present study provides a long-term representation of German Bight barotropic flow conditions in terms of few PCs on a daily basis without any seasonal gaps (data are freely available from Callies (2016). In comparison to previous studies, the new data refine the timescale (daily instead of monthly) and/or the spatial focus (German Bight instead of the whole North Sea). The correspondence of PCs with different directions of wind forcing is analysed. An example illustrates the characterization of meteo-marine conditions at Helgoland Roads during a selected 2 month period. The relationship between daily PCs and their counterparts obtained from a PCA based on monthly mean fields is investigated.

\section{Methods}

\section{Hydrodynamic simulations}

The present study draws on two-dimensional (the vertical coordinate remains unresolved) marine current simulations with the model TRIM-NP for the North Sea. Snapshots of model output stored once per hour (Gaslikova and Weisse 2013) are available for the period Jan. 1948-Aug. 2015. The hourly resolution being insufficient to fully resolve ebb and flood maxima is not an issue for the present study focussed on residual currents. The analysis is confined to data from the period Jan. 1958-Aug. 2015. The 10 years of data before 1958 are disregarded because hindcasts of atmospheric forcing for this period seem less reliable (Kistler et al. 2001). 
TRIM-NP is a hydrodynamic model that solves the 3D Reynolds-averaged Navier-Stokes equations on a Cartesian grid. It allows for wetting and drying. The numerics and some validations can be found in Casulli and Stelling (1998); some extensions concerning parallelization and nesting are described in Kapitza (2008). The data used here were produced running TRIM-NP in a two-dimensional hydrostatic and barotropic mode. The coarsest grid with a resolution of $12.8 \mathrm{~km}$ covers the whole North Sea and Baltic Sea, and the north-eastern Atlantic. Three grid refinements are nested oneway into the domain with a finest resolution of $1.6 \mathrm{~km}$ over the German Bight (cf. Fig. 1). Tidal signals at the lateral boundaries of the coarsest grid are determined from the FES2004 tidal model (Lyard et al. 2006). Atmospheric forcing by wind and sea level pressure is taken from regional COSMO-CLM hindcasts (Geyer 2014). Note that for display purposes the original model currents on Cartesian grids were transformed into geographical coordinates.

The simulations underlying the present study are just one element of the more comprehensive met-ocean data base coastDat-2 described in Weisse et al. (2015). Weisse et al. (2015) provide results of data validation and summarize a spectrum of applications.

\section{Definition of residual currents}

Residual current fields on a daily basis were derived by averaging velocity fields over $25 \mathrm{~h}$ starting at midnight. The averaging interval of about one lunar day (24.8 h) was chosen to eliminate tidal currents as effectively as possible. In addition, monthly averages were specified. In this way 21,061 daily and 692 monthly residual current fields were generated within the period Jan. 1958-Aug. 2015.

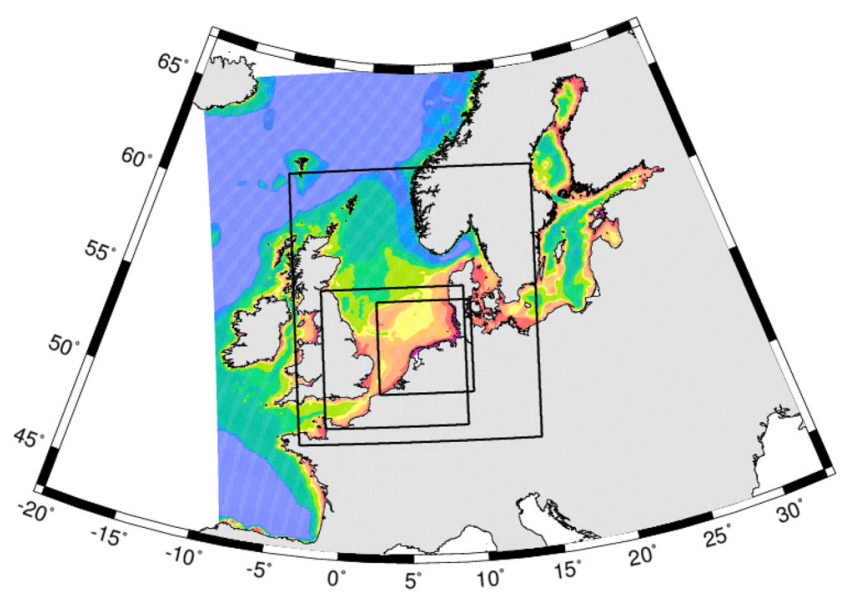

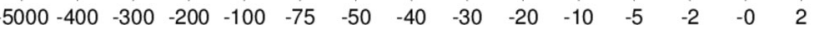

Fig. 1 Nested setup for the hydrodynamic model TRIM-NP (grid resolutions: $12.8 \mathrm{~km} / 6.4 \mathrm{~km} / 3.2 \mathrm{~km} / 1.6 \mathrm{~km}$ )
Figure 2 presents the long-term mean currents to which all time-dependent residual current anomalies refer. The study focuses on the inner German Bight region east of $6.0^{\circ} \mathrm{E}$ and south of $55.6^{\circ} \mathrm{N}$ (white box in Fig. 2). Inshore sectors with a bathymetric depth of less than $10 \mathrm{~m}$ were excluded to avoid the analysis being influenced by small-scale coastal features. As a result, each residual current field comprises $2 \mathrm{D}$ velocity vectors on 12,133 grid points.

\section{Principal component analysis (PCA)}

Let $M$ elements of state vector $\vec{X}(t)$ comprise two velocity components per grid node. Then PCA provides the following decomposition of $\vec{X}(t)$ :

$\vec{X}(t)=\vec{X}_{0}+\sum_{i} \alpha_{i}(t) \vec{e}_{i}$

where $\vec{X}_{0}$ represents the mean velocity field (cf. Fig. 2). Variations of $\vec{X}$ in time $t$ are represented by a superimposition of spatially coherent deviations from $\vec{X}_{0}$, expressed in terms of a set of fixed anomaly patterns $\vec{e}_{i}$ (displayed in Fig. 3). Principal components (PCs) $\alpha_{i}(t)$ provide the time-dependent amplitudes of these anomaly patterns.

The constant orthogonal vectors $\vec{e}_{i}$ of length $M$ are called empirical orthogonal functions (EOFs). If they are normalized

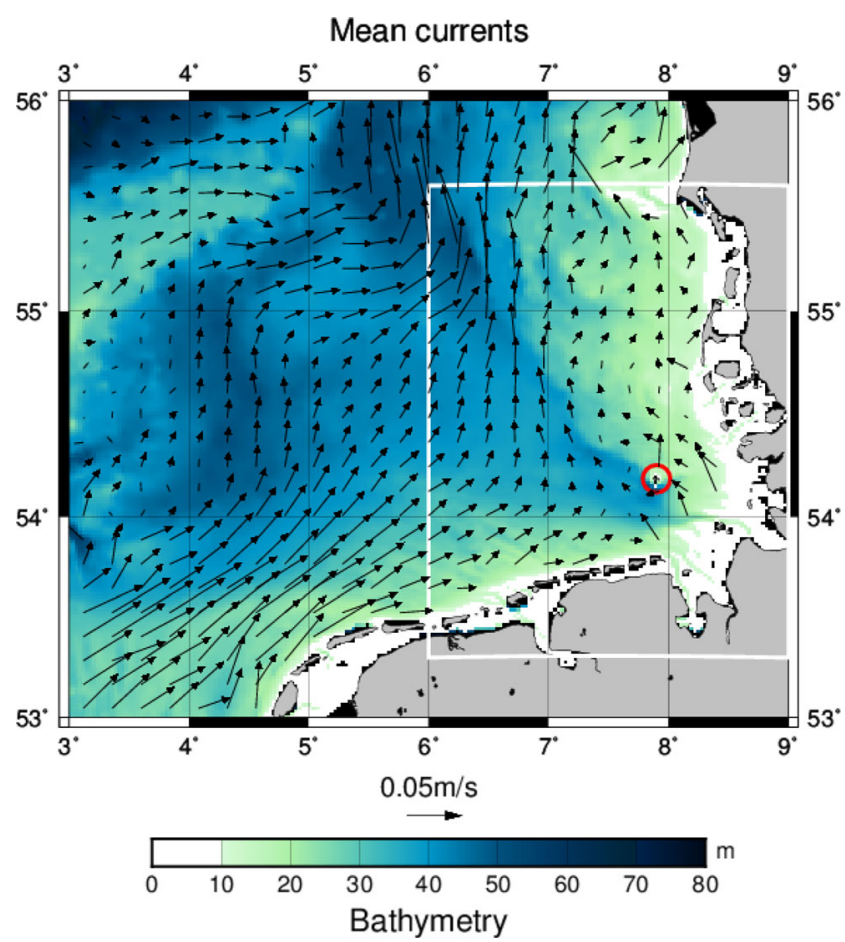

Fig. 2 Mean currents (Jan. 1958-Aug. 2015) within the German Bight (North Sea). White box Focus area considered in this study. The density of vectors plotted does not reflect grid resolution (only every eighth vector is plotted). Red circle Location of Helgoland Roads 
to unit length, then the value $\alpha_{i}(t)$ of the corresponding PC can be calculated by a simple projection of vector $\vec{X}(t)$ onto $\vec{e}_{i}$ :

$\alpha_{i}(t)=\left(\vec{X}(t)-\vec{X}_{0}\right)^{T} \vec{e}_{i}$

where superscript $T$ denotes a row vector obtained as the transpose of the original column vector. Note that the orientation of EOFs $\vec{e}_{i}$ may be selected according to one's liking. Changing the orientation of $\vec{e}_{i}$ implies, however, also a multiplication of the corresponding time series $\alpha_{i}(t)$ with -1 .

Technically, the EOFs $\vec{e}_{i}$ are eigenvectors of the $M \times M$ covariance matrix (e.g. von Storch and Zwiers 1999). For the present study, the large number of grid nodes $(M=2 \times 12,133)$ renders a conventional PCA impossible. To overcome this problem, Scharfe (2013) interpolated model output to a much coarser grid. Alternatively, a formal reversal of the roles of independent variables and time levels and a retransformation of PCA results can reduce computational demands (e.g. Section 13.2.6 in von Storch and Zwiers 1999). For $N=692$ fields of monthly mean currents, indeed this makes a PCA feasible. However, for $N=21,061$ daily fields it is still prohibitive. Therefore, for daily data the approach taken in this study is to partition the 57.7 year period into shorter periods of one decade at most (about 3,650 time levels; cf. listing in Table 1). EOFs analysed for six different sub-periods were then averaged to obtain anomaly patterns representative for the full period Jan. 1958-Aug. 2015. Based on these averaged EOFs, PC time series were calculated using Eq. 2. Both the raw data and results of PCA are available from the Climate and Environmental Retrieval and Archive (CERA) of the Deutsches Klimarechenzentrum (Callies 2016).

\section{Results}

\section{PCA of daily residual currents}

Figure 3 presents the three leading modes of variability (in terms of overall variance they represent), resulting as averages of those obtained from six PCAs conducted for each sub-period listed in Table 1 independently. The structure of $E O F_{1}$ resembles the counter-clockwise mean circulation (cf. Fig. 2), so that $P C_{1}>0$ describes a strengthening and $P C_{1}<0$ a weakening (including reversal) of the mean circulation. By contrast, $E O F_{2}$ represents a southward transport of coastal waters and its subsequent discharge into the open North Sea. $\mathrm{EOF}_{3}$ represents transport towards the south-eastern coast of the German Bight and an eddy-like structure centred at the island of Helgoland.

Daily PC values were obtained by projecting (see Eq. 2) residual current fields onto the EOFs shown in Fig. 3. Figure 4 compares moving annual averages of these values with simple a

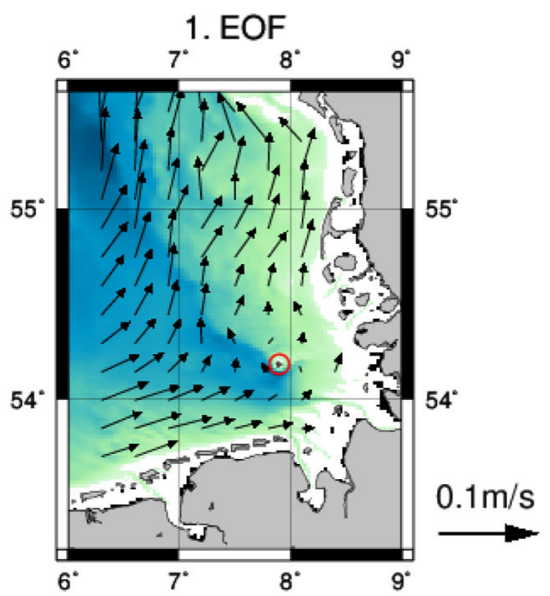

b

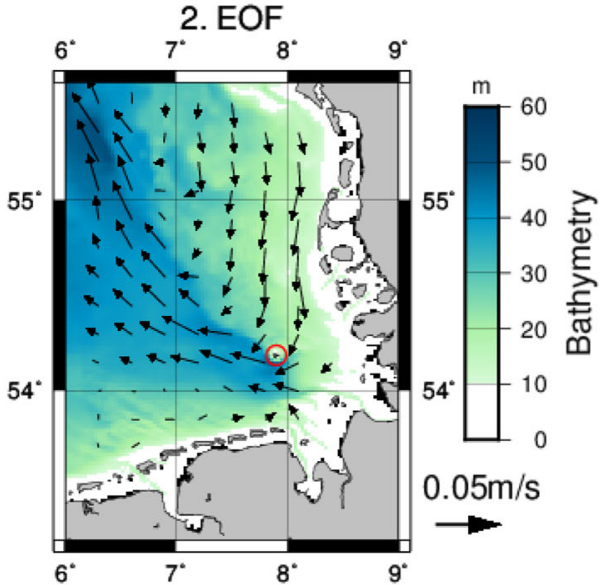

C

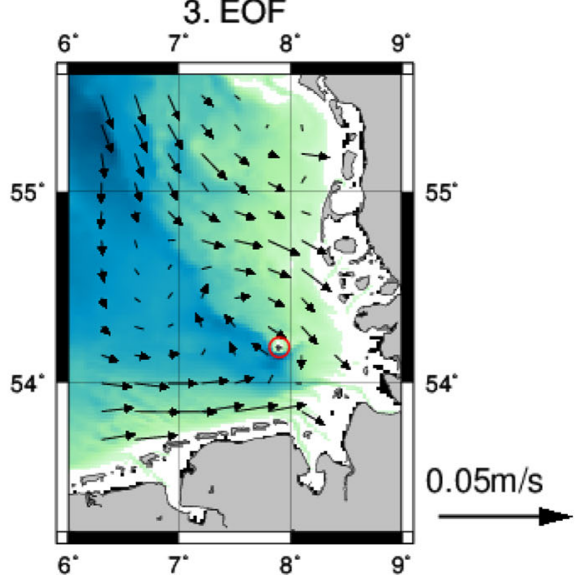

Fig. $3 E O F_{1}, E O F_{2}$ and $E O F_{3}$ obtained from PCA of daily residual currents $(25 \mathrm{~h}$ means). The originally normalized (and therefore dimensionless) vector fields were multiplied with the standard deviation of the corresponding PCs. Accordingly, each panel shows an anomaly component in a state when the respective $\mathrm{PC}$ has the value of one standard deviation. Red circles Location of Helgoland Roads

composites of exact values obtained for each of the six subperiods independently. All PCs were normalized prior to averaging; for the composites, normalization was performed considering all six time series jointly. The results reveal very close correspondence, in agreement with the fact that 
Table 1 Explained variances (\%) of PCs for different periods

$\begin{array}{llll}\text { Period } & P C_{1} & P C_{2} & P C_{3}\end{array}$

Daily residual currents
Jan. 1958-Dec. 1965

Jan. 1966-Dec. 1975

74.9

71.9

72.2

74.5

72.9

73.7

83.9

Jan. 1958-Aug. 2015

Jan. 1996-Dec. 2005

Jan. 2006-Aug. 2015
3.7

4.4

4.0

3.7

3.9

3.9 percentages of explained variance were found to be similar for different decades (cf. Table 1). Small biases can possibly be attributed to the fact that the mean circulations the anomalies refer to are not exactly the same for different decades.

Figure 5 exemplifies values of $P C_{1}, P C_{2}$ and $P C_{3}$ on a daily basis for 4 years. PC variability tends to be smallest in summer. Each of the three PCs was scaled with the standard deviation of $P C_{1}$ so as to maintain the information about relative contributions from each PC (cf. after normalization, all EOFs have the same length). According to Table 1, the first three PCs already explain more than $90 \%$ of overall variability, so that daily residual current fields can efficiently be reconstructed based on these very few degrees of freedom. An example is given below.

\section{PCA of monthly residual currents}

For both $E O F_{1}$ and $E O F_{2}$ the patterns obtained based on PCA of monthly residual currents (not shown) closely resemble those in Fig. 3. Accordingly, monthly means of daily PCs compare well with those analysed directly from monthly fields. For $P C_{1}$ the correlation is nearly perfect (Fig. 6a) and, for $P C_{2}$, very high (Fig. 6b). However, the two analyses differ completely with regard to $P C_{3}$ (Fig. 6c) and the structure of $\mathrm{EOF}_{3}$ (not shown).

Periods during which daily $P C_{2}$ and $P C_{3}$ have large absolute values tend to cluster. As an example see Nov./Dec. 1973 in Fig. 5b, when the German North Sea coast experienced one of the most severe chains of storm floods in living memory (Lamb 1991). Another storm flood event in Feb. 1962 is addressed in detail below. Small time lags between daily $P C_{2}$ and $P_{3}$ values remain unresolved on a monthly timescale. Therefore, clusters of joint large excursions generate a substantial correlation $\left(\mathrm{R}^{2}=0.46\right)$ between monthly averages of daily $P C_{2}$ and $P C_{3}$ values, which (by construction) does not exist for the original daily values. By contrast, monthly averaging of daily values does not generate substantial correlations between $P C_{1}$ and $P C_{2}$ or $P C_{1}$ and $P C_{3}$.

\section{Low-dimensional representation of daily residual currents}

An example demonstrates the efficacy of a low-dimensional approximation of daily residual velocities. The most extreme value of $\mathrm{PC}_{2}$ occurs on the second day (17 Feb. 1962; see Fig. 5a) of the disastrous storm flood of 1962 in Hamburg (Lamb 1991). The panels of Fig. 7a-c show residual currents simulated for this day, the day before, and for 15 March when the system returned to a more common situation with just an intensified mean residual circulation (compare Fig. 2). Reconstructions keeping only the first three summands in Eq. 1 are shown in the panels of Fig. $7 \mathrm{e}-\mathrm{g}$. They all replicate corresponding original fields closely. Some differences occur on 15 March, when the reconstruction produces smaller velocities to the north of Helgoland. According to Fig. $7 d$ (zooming into Fig. 5a), the very intense transport of water from inshore regions towards the open North Sea on 17 Feb. is related to the high value of $P C_{2}$, but building up the eddylike structure the day before is related to the high value of $P_{3}$
Fig. 4 Moving annual averages of approximate PCs obtained by projecting daily fields onto average EOFs from the six subperiods listed in Table 1 (coloured). These values are contrasted with averaged simple composites of exact PCs calculated for each sub-period independently (black). The splitting into sub-periods (cf. Table 1) is indicated by dashed vertical bars. Prior to averaging, each time series was divided by its overall standard deviation

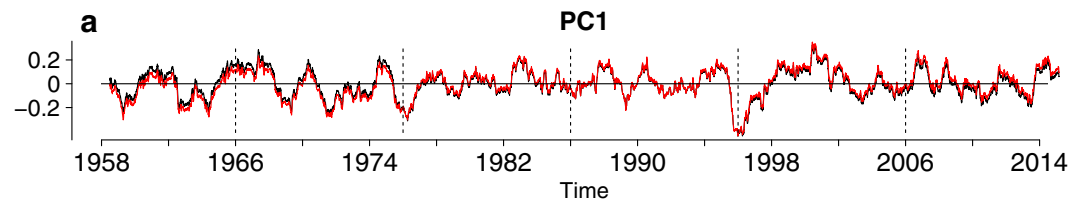

PC2
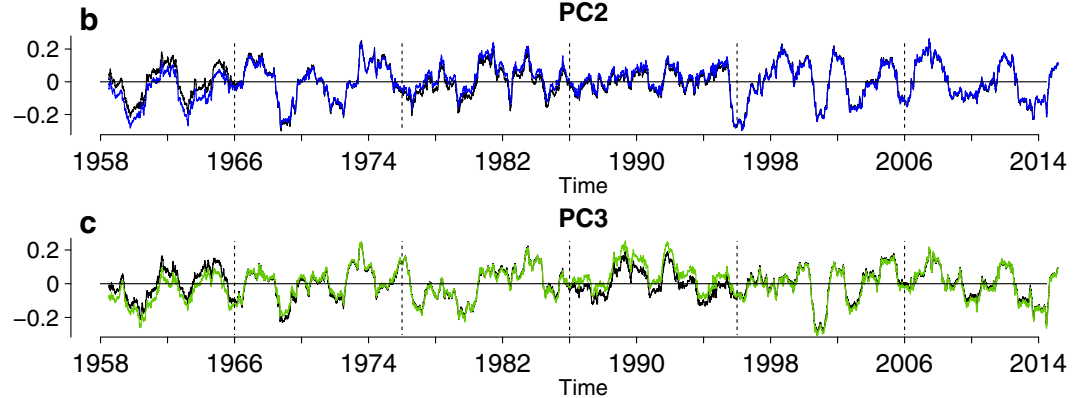
Fig. 5 Daily values of $P C_{1}$ (red), $P_{2}$ (blue) and $P C_{3}$ (green) for 4 selected years. Each of the 3 PCs was scaled with the standard deviation of $P C_{1}$ (with regard to the full period Jan. 1958Aug. 2015) a

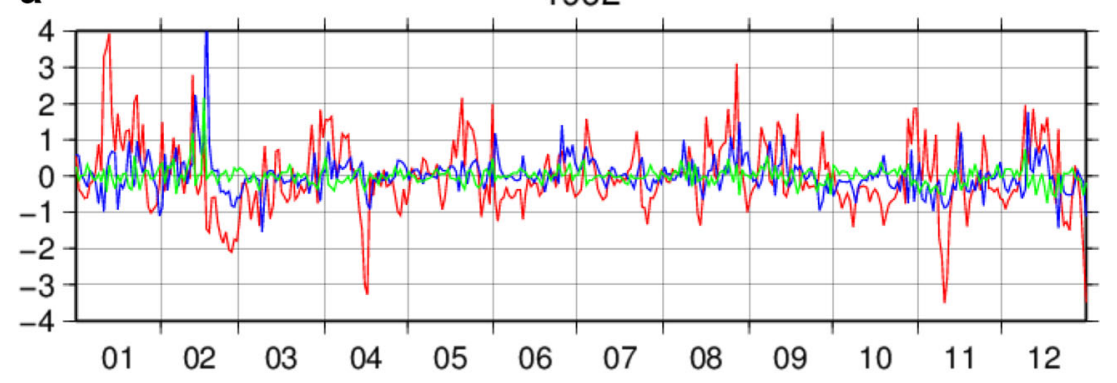

b

1973
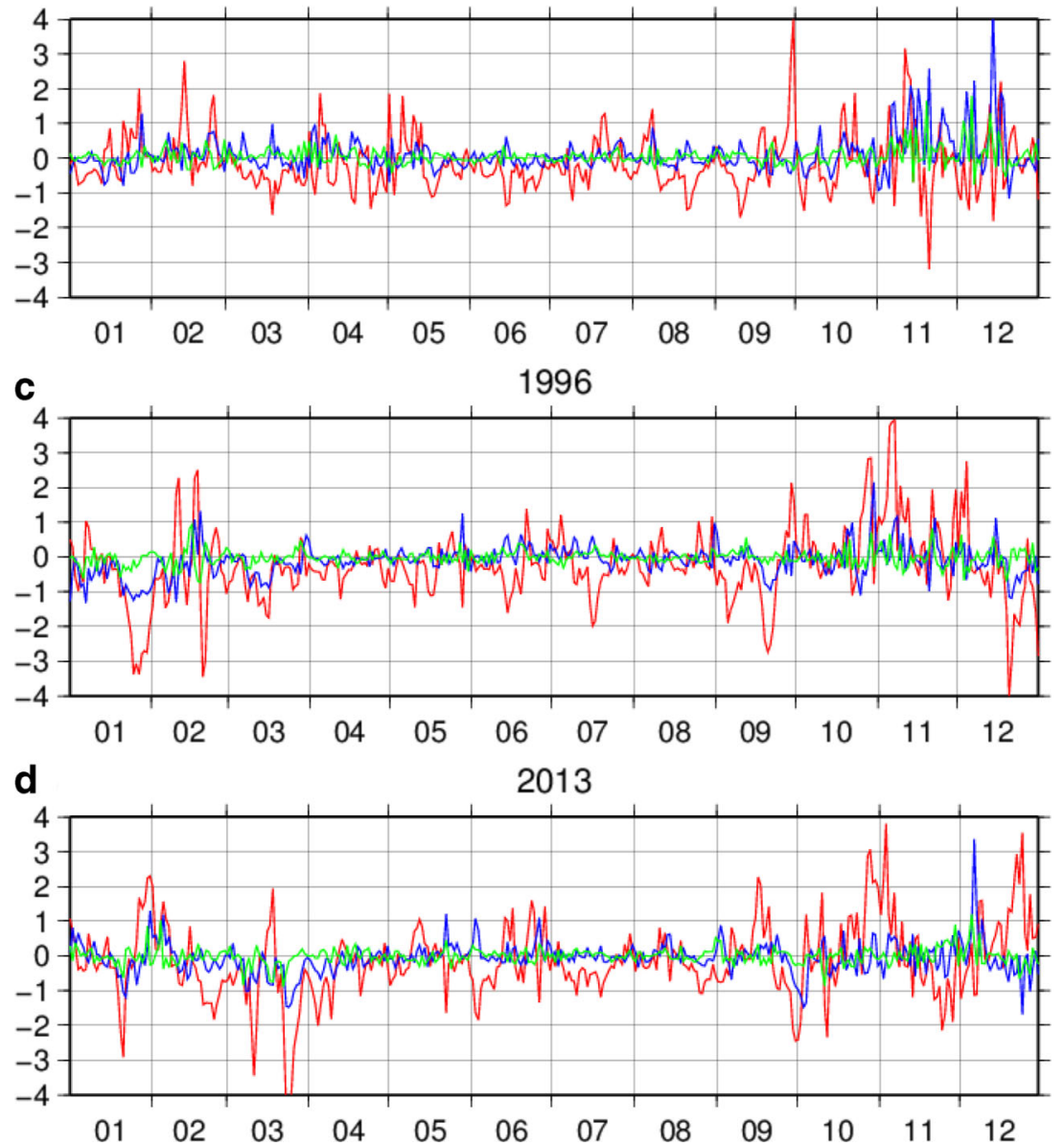

(cf. Fig. 3c). For many other periods $P C_{3}$ is negligible and indeed, for $17 \mathrm{Feb}$. and $15 \mathrm{Mar}$., residual currents could equally well have been estimated based on only $P C_{1}$ and $P C_{2}$.

The second largest value of $P C_{2}$ occurs on 14 Dec. 1973, the endpoint of a 4 week period with severe storms already addressed above (cf. Fig. 5b). Note, however, that the predominance of any event in the present analysis also depends on its timing relative to the period for which daily mean currents were defined (here $25 \mathrm{~h}$ starting at midnight).

The reason why an extreme event was selected as an example is that it shows most clearly the possible joint role played by PCs in representing the succession of different phases of atmospherically forced changes in marine circulation. Under more regular conditions the time variability of PCs is less structured, as exemplified below for a 2 month period (cf. Fig. 9).

\section{Relationship with atmospheric forcing}

Figure 8 illustrates the relationships between the two leading PCs and atmospheric wind conditions. Wind data $(10 \mathrm{~m}$ height) at location $7.5^{\circ} \mathrm{E}$ and $54.5^{\circ} \mathrm{N}$ were extracted from the atmospheric forcing used for hydrodynamic simulations. For each of the two leading PCs the full set of days was partitioned into those with positive or negative PC values. Then for both of these subsets the relative frequencies of 

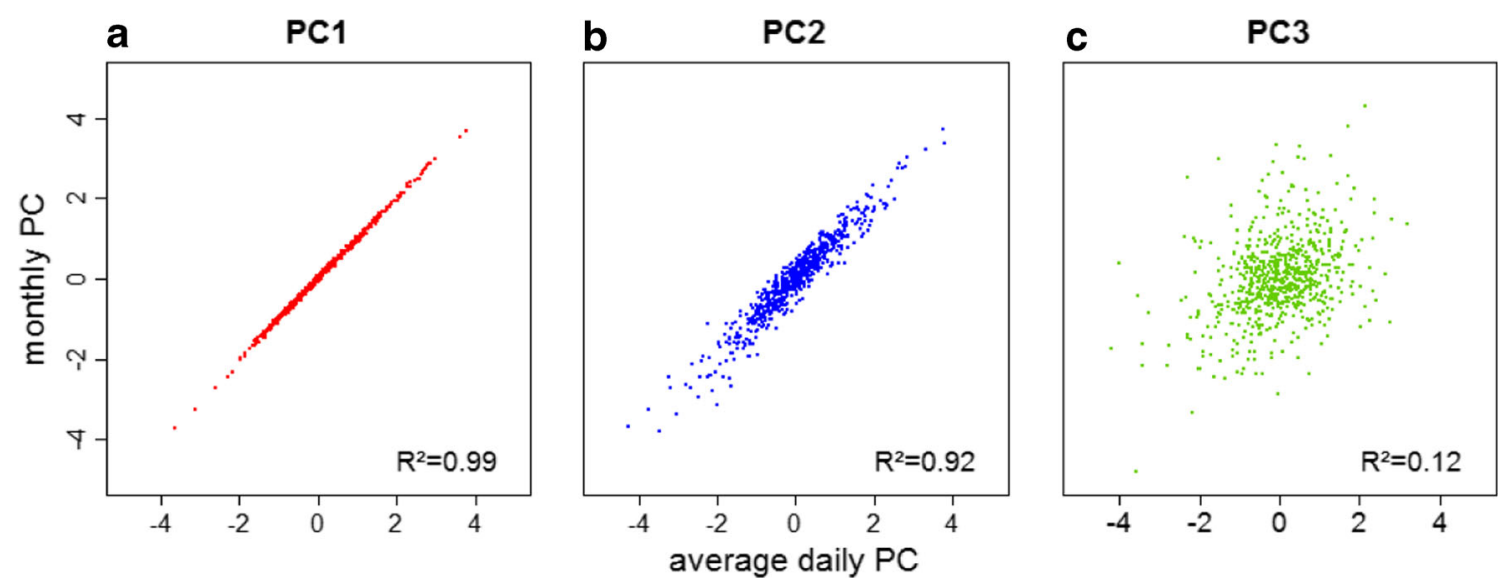

Fig. 6 Monthly means of daily PCs versus corresponding values obtained directly from PCA of monthly mean fields. Each PC time series was scaled by its respective standard deviation

winds blowing from each of eight different sectors were specified. Figure 8 shows these relative frequencies (dependent on the sign of a selected PC) divided by corresponding overall frequencies no matter what the PC values are. Values larger (smaller) than 1 indicate that, given the assumed sign of a PC, winds blowing from this sector are more (less) likely than on average.

According to Fig. 8a, the probability of winds blowing from SE-W sectors is higher if $P C_{1}$ values are positive, and the probability of winds blowing from any of the opposite sectors (NW-E) is higher if $P C_{1}$ values are negative. Considering $\mathrm{PC}_{2}$, there are more frequent winds from $\mathrm{SW}-$ $\mathrm{N}$ for positive values and from NE-SW for negative values. Generally, all distributions become slightly more concentrated when the simple differentiation between positive and negative PCs is sharpened by the introduction of threshold values (e.g. \pm 0.5 or \pm 1 ) that discard all cases with small or even intermediate PC values (not shown).

\section{Local monitoring data: an example}

Figure 9 illustrates the use of information on residual current variability for characterizing hydrodynamic conditions during a 2 month period (July-August 2012) spanning two events of decreased salinity at Helgoland Roads. The second event coincides with the beginning of a field campaign (626 Aug.) that examined the dynamics of bacterial community composition. Lucas et al. (2016) showed that the onset of a shift in the bacterioplankton community at Helgoland Roads was triggered by changes in the hydrodynamic regime.

Figure 9 combines daily salinity values with corresponding time series of $P C_{1}$ and $P C_{2}$. Both salinity minima coincide with negative excursions of $P C_{1}$ that lead to even a reversal of the usually counter-clockwise circulation (not shown). Superimposed on this is a transition of $P C_{2}$ from positive to negative values near the salinity minimum (particularly pronounced during the second event). According to Fig. $3 \mathrm{~b}$ this implies a decreasing advection of coastal waters followed by increasing advection from the open North Sea. Figure 9 does not show values of $P C_{3}$ as these are small throughout the whole period.

\section{Discussion}

A series of previous studies already used PCA for assessing variability of North Sea circulation. However, they all concentrated on long-term behaviour and were based on monthly or even seasonal mean data. By contrast, the daily data provided here have the same time resolution as monitoring information gathered at Helgoland Roads, for instance. To make the highresolution PCA feasible, the 57.7 year study period was subdivided into several decades. Partial results were then recombined into one joint representation, which was successfully checked against exact results for each sub-period (Fig. 4). An important by-product of this technically required approach is that it confirmed the stability of results obtained.

It was shown that daily barotropic residual current fields in the German Bight can be approximated in terms of only 2-3 PCs plus corresponding spatial patterns of deviations from mean conditions (EOFs). The third EOF (Fig. 3c) represents strong transport towards the coastal regions of the inner German Bight, and seems relevant only in the context of major storm events. Screening many different situations shows that in the majority of cases already the first two modes of variability enable a reasonable description of conditions in the inner German Bight. The high spatial resolution $(1.6 \mathrm{~km})$ underlying this study well represents details of currents affecting conditions at Helgoland Roads, for instance. Although the first mode explains well above $70 \%$ of overall variability in the German Bight, its contribution in the vicinity of Helgoland is very limited (cf. Fig. 3a). In this respect it agrees with the mean currents, which are also small in this area (Fig. 2). By contrast, $\mathrm{EOF}_{2}$ (Fig. 3b) concentrates on southward advection 
Fig. 7 Top Simulated residual currents ( $25 \mathrm{~h}$ mean fields) for the 3 days (16/17 Feb. and 15 Mar. 1962) indicated by dashed vertical bars in the PC time plot. Bottom Residual currents reconstructed based on $3 \mathrm{PCs}$ shown in panel d. Note that velocity vectors were scaled differently for different days. The PC time plot zooms into Fig. 5a, i.e. each of the three time series was scaled with the standard deviation of $P C_{1}$, considering the full period for which data exist

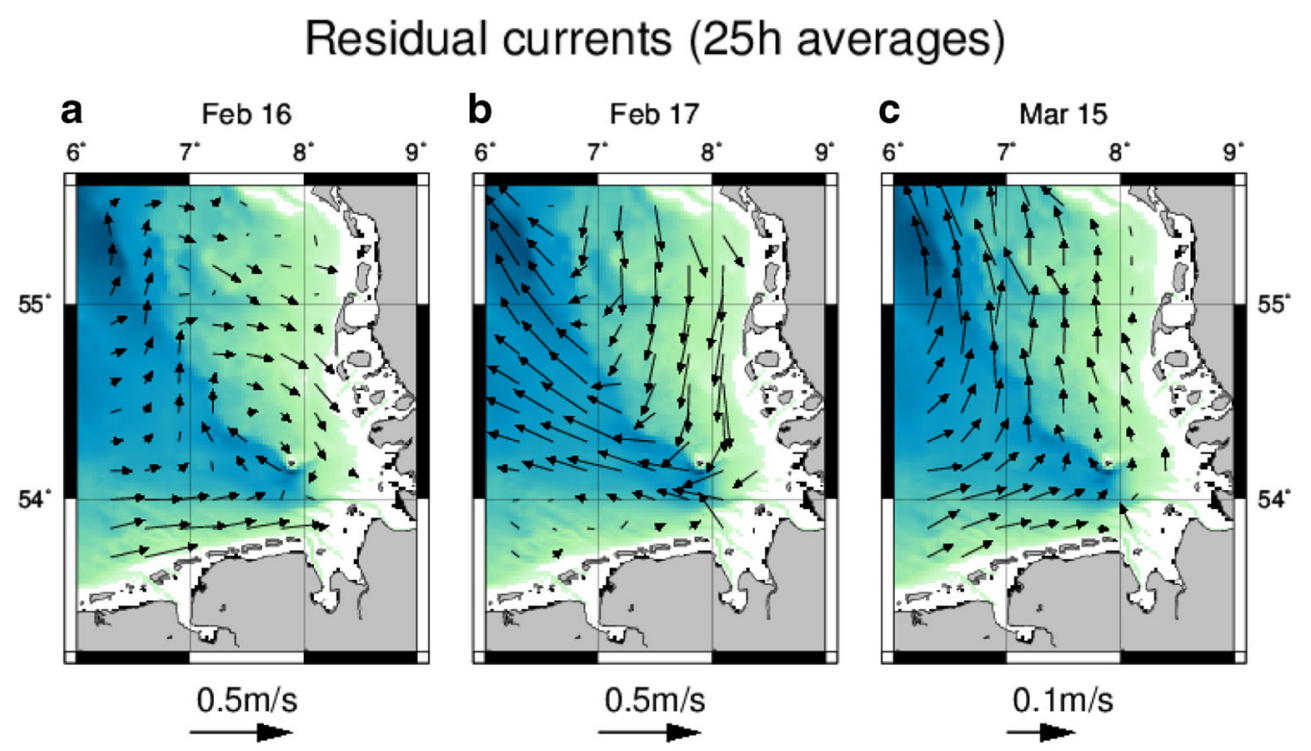

Reconstructions based on 3 PCs

d $\quad$ PC1(red), PC2(blue), and PC3(green) for Feb-Mar 1962
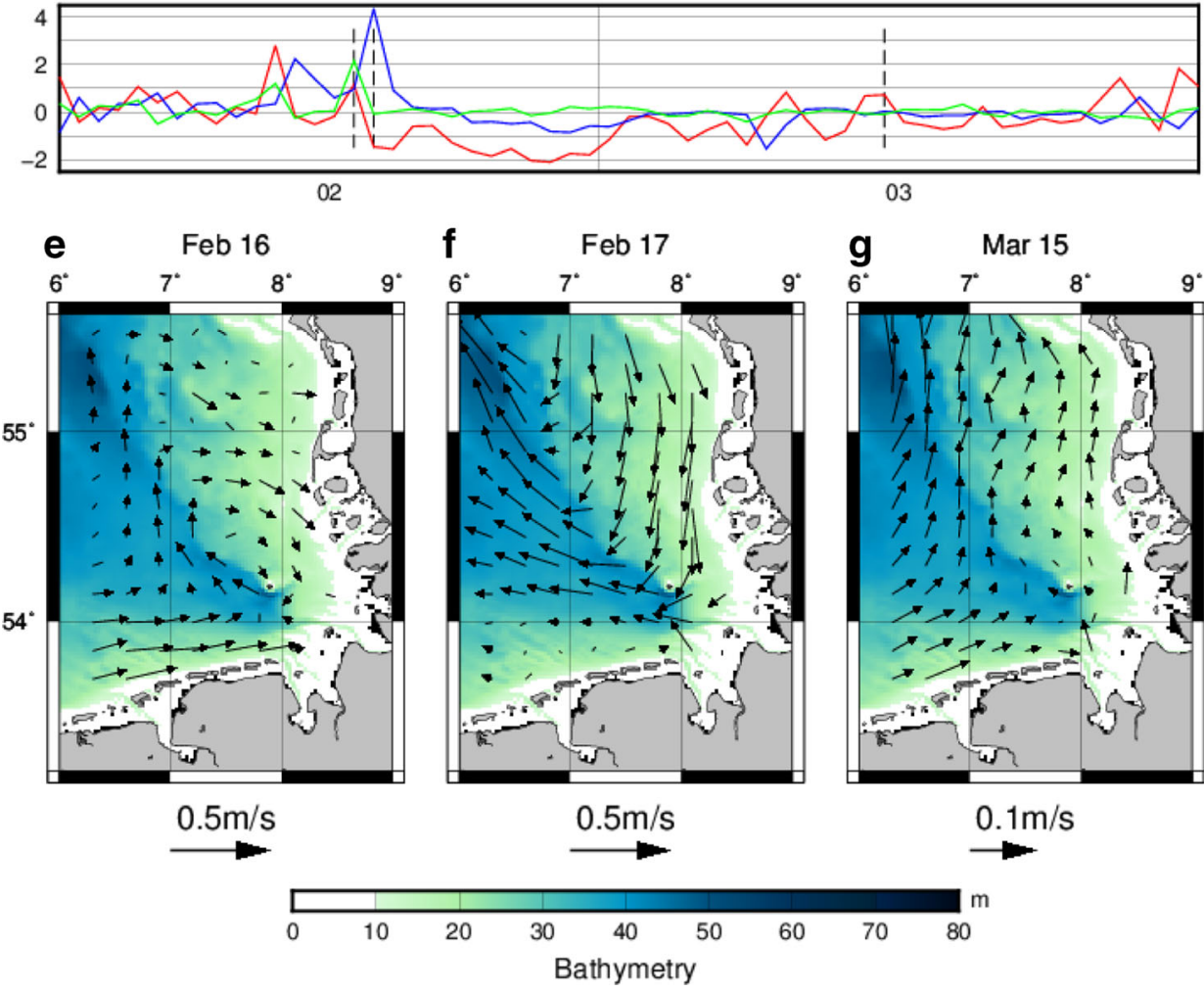

Due to the mathematical orthogonality constraints (for PCs in time, for EOFs in space) involved in PCA, choices of scales must be expected to affect the outcomes of these analyses. For checking implications of the chosen timescale, the PCA was repeated for residual currents derived as monthly rather than $25 \mathrm{~h}$ mean fields. While the first two modes of variability were found to be similar in both cases, the third modes differed 

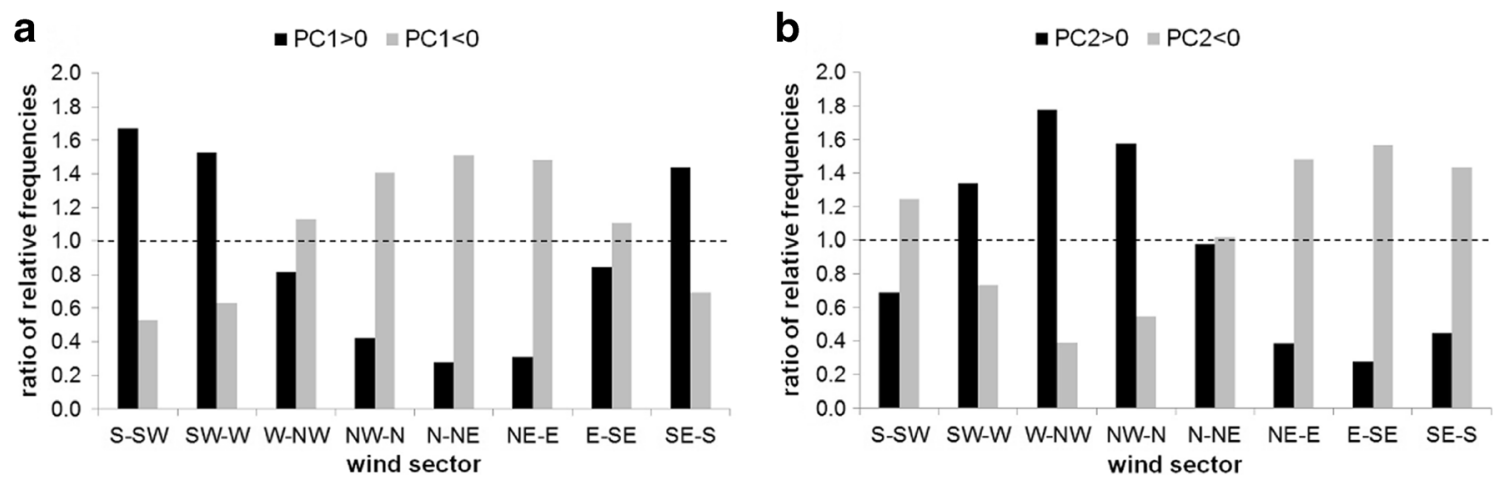

Fig. 8 Correspondence between the signs of $P C_{1}$ or $P C_{2}$ and relative frequencies of wind directions resolved in terms of a wind rose with eight different sectors. Histograms show ratios of relative frequencies conditional on a given PC sign to unconstrained relative frequencies

completely in terms of both the structure of $\mathrm{EOF}_{3}$ (not shown) and the time behaviour of $P C_{3}$ (Fig. 6c). More efficient averaging could result in the remainders of tidal currents being represented by lower-ranking PCs in the monthly mean than in the $25 \mathrm{~h}$ mean residual currents.

Mathis et al. (2015) mention that results of their PCA of the general circulation on the northwest European shelf were not very sensitive to the exact domain size. To examine how domain specific the results of the present study are, the whole analysis was repeated for the full domain shown in Fig. 2 . Within the overlapping sector, $E O F_{1}$ obtained for the wider domain (not shown) very much resembles its counterpart in Fig. 3. Accordingly, also $P C_{1}$ time series are very similar. By contrast, $E O F_{2}$ for the larger domain (not shown) seems dominated by stronger residual currents outside the focus area of the inner German Bight (cf. Fig. 2).

PC time series represent effects of changing wind forcing on residual currents. Direct effects of tides on residual currents are generally small, notwithstanding that notable effects may arise from nonlinear interactions (Backhaus 1989). In some studies PCA has been applied for analyzing variability of currents derived from HF radar data. For example, Zhao et al. (2011) and Lana et al. (2016) report two leading PCs related to specific wind directions. According to Fig. 8, this is also the case for the daily PCs of depth-averaged residual currents in the German Bight. The negative of $E O F_{2}$ resembles the corresponding segments of vertically averaged North Sea residual current patterns shown in Pingree and Griffiths (1980, their
Fig. 4), assuming uniform wind stresses from the southeast. This agrees with the finding that, according to Fig. 8b, negative values of $P C_{2}$ should be related to winds blowing from the southeast.

On inter-annual timescales, the winter North Sea general circulation is often parametrized in terms of variations of the North Atlantic Oscillation (NAO) winter index (Hurrell 1995) as a proxy for atmospheric variability (e.g. Hurrell and Dickson 2005; Beaugrand 2009; Kim et al. 2013). Leterme et al. (2008) attribute winds from the southeast to negative and winds from the southwest to positive NAO phases. According to Fig. 8, winds from the southwest are likely to coincide with positive values of $P C_{1}$. Also Mathis et al. (2015) found that $P C_{1}$ of their seasonal data related to a strengthening or weakening of the counter-clockwise circulation in the German Bight was positively correlated with the NAO. They attributed the absence of relationships with NAO for higherorder PCs to an interaction between different wind-induced modes of variability in the general marine circulation. Scharfe (2013) found that both $P C_{1}$ and $P C_{2}$ resulting from a PCA of monthly mean volume fluxes in the German Bight were positively (after adjusting for the different sign of $E O F_{2}$ in Scharfe (2013)) correlated with NAO in winter. Two PCs being correlated with NAO indirectly confirms the results of Mathis et al. (2015) as it indicates the existence of an additional degree of freedom uncontrolled by the single variable NAO. The favourable comparison of daily data with the results of a PCA based on monthly data (Fig. 6) implies that time
Fig. $9 P C_{1}($ red $)$ and $P C_{2}$ (blue) are contrasted with salinity values (black dashed) observed at Helgoland Roads during July and August 2012. Both PCs were normalized with the standard deviation of $P C_{1}$

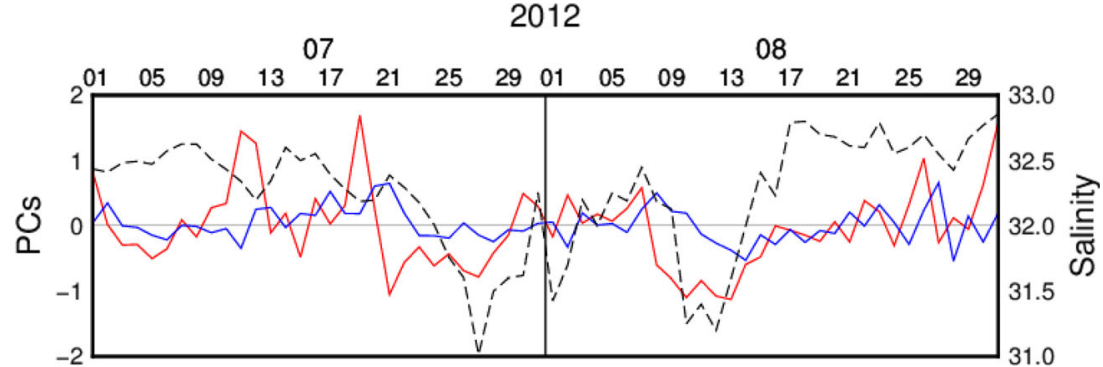


averaging of daily PCs reproduces the seasonal interaction with NAO. However, for resolving daily conditions the use of the NAO as a proxy is not reasonable.

In agreement with low-dimensional representations of atmospheric variability on an inter-annual seasonal scale, Oliver et al. (2015) found also variations of larval transport in response to variable atmospheric forcing to have only a few degrees of freedom. On a much shorter timescale, Fig. 9 suggests that time behaviour of residual current PCs can be interrelated with local salinity observations at Helgoland Roads. It should be kept in mind that different PCs do not represent physically distinct processes, the splitting of overall variability into different modes being simply a statistical decomposition. Instead of correlating with single PCs, locally observed data could coincide with the occurrence of certain patterns of combined time behaviour of $P C_{1}$ and $P C_{2}$, for instance. Figure 7 provides an example for such succession of $\mathrm{PC}$ values in the context of storm floods. In relating winds and surface circulation patterns, Solabarrieta et al. (2015) replaced PCA by more advanced neural network methods and clustering algorithms. If, however, the objective is to provide generic time series that can easily be used within the context of any further analysis, then the simple and transparent interpretation of PCs and corresponding EOFs is an advantage that should not be discarded.

The present study proposes efficient harnessing of basic hydrodynamic information and making this accessible also for a non-modeller community. One major simplification is that effects of stratification and vertical shears of velocity remained unresolved in the underlying $2 \mathrm{D}$ simulations. PCA of full 3D model output would be computationally much more demanding and also provide higher dimensional output. In their large-scale studies, Emeis et al. (2014) and Mathis et al. (2015) therefore either integrated or averaged 3D model results in the vertical. Calculating daily PCs of residual currents based on 3D simulations in the German Bight is a challenge for future studies.

Van der Veer et al. (1998) suggest that inter-annual variability of wind-induced marine circulation has large impacts on year-class strengths of various fish species in the southern North Sea, for instance. They also mention, however, that correlations of transport with other environmental parameters like salinity or temperature are important as well. Based on process-oriented model simulations, Daewel et al. (2015) confirm the relevance of both these factors for larval survival. Against this background, referring to simple PCs might appear to lag behind what state-of-the-art ecosystem models are able to simulate in much greater detail. However, the comprehensive discussion of the difficulties to properly calibrate and validate "large" models from existing field data provided by Beck $(1983,1987)$ is still valid today, and the use of mecha- nistic ecosystem models is not beyond dispute (e.g. Pätynen et al. 2013; Planque 2016). Depending on the specific application, PCs derived in this study could also be efficient proxies for more complex conditions than simply marine transport.

\section{Conclusions}

Knowing patterns of residual currents and corresponding transport is relevant for a proper interpretation of spatially distributed monitoring data. PCA allows for a concise description of residual current variability in terms of changing amplitudes of fixed spatial anomaly patterns. Former studies providing residual current PCs for the German Bight on a monthly timescale already contributed to a better explanation of inter-annual changes of mean nutrient concentrations observed at Helgoland Roads. However, monthly PCs cannot adequately address the full potential of monitoring data sampled with high resolution in time. The present study remedies this situation by characterizing lateral transport in the German Bight on a daily basis.

Averaging the two leading daily PCs more or less reproduces results from a PCA of monthly mean fields. In former studies on an inter-annual timescale, $P C_{2}$ was found to be the most relevant PC for Helgoland Roads data. The example shown in Fig. 9 suggests that, for short-term changes of local conditions, both $P C_{1}$ and $P C_{2}$ are relevant indicators. Each PC is related to a dominant wind direction and represents a characteristic type of advection of water masses towards the monitoring station. To which extent effects analysed on longer timescales can be explained as aggregated short-term events requires forthcoming studies.

Hydrodynamic information in terms of PCs can easily be incorporated into the context of more comprehensive data analyses. However, one must be aware that generally residual current PCs also act as proxies for variable weather conditions in a wider sense. Having found a correlation between a residual current PC (possibly its average over longer periods) and any other variable of interest, it therefore remains for the second step of a two-step procedure to check whether or not the structure of the corresponding EOF justifies a direct mechanistic interpretation of the correlation identified.

Acknowledgments The study was conducted in close connection with the WIMO project (Scientific Monitoring Concepts for the German Bight), jointly funded by Niedersächsisches Ministerium für Wissenschaft und Kultur (MWK) and Niedersächsisches Ministerium für Umwelt, Energie und Klimaschutz (MU). The final manuscript much benefited from the helpful comments of two anonymous reviewers. 


\section{Compliance with ethical standards}

Conflict of interest The authors declare that there is no conflict of interest with third parties.

Open Access This article is distributed under the terms of the Creative Commons Attribution 4.0 International License (http:// creativecommons.org/licenses/by/4.0/), which permits unrestricted use, distribution, and reproduction in any medium, provided you give appropriate credit to the original author(s) and the source, provide a link to the Creative Commons license, and indicate if changes were made.

\section{References}

Backhaus JO (1989) The North Sea and the climate. Dana 8:69-82

Beaugrand G (2009) Decadal changes in climate and ecosystems in the North Atlantic Ocean and adjacent seas. Deep-Sea Res II 56:656673

Beck MB (1983) Uncertainty, system identification, and the prediction of water quality. In: Beck MB, van Straten G (eds) Uncertainty and forecasting of water quality. Springer, Berlin, pp. 3-68

Beck MB (1987) Water quality modeling: a review of the analysis of uncertainty. Water Resour Res 23:1393-1442

Callies U (2016) coastDat-2 Hydrodynamic Model TRIM-NP Principal Component Analysis Residual Currents. World Data Center for Climate (WDCC) at DKRZ. doi:10.1594/WDCC/TRIM-NP-2dPCA ResCurr

Callies U, Scharfe M (2015) Mean spring conditions at Helgoland Roads, North Sea: graphical modeling of the influence of hydro-climatic forcing and Elbe River discharge. J Sea Res 101:1-11

Casulli V, Stelling GS (1998) Numerical simulation of 3D quasi-hydrostatic, free-surface flows. J Hydraul Eng 124:678-686

Crise A, Allen JI, Baretta J, Crispi G, Mosetti R, Solidoro C (1999) The Mediterranean pelagic ecosystem response to physical forcing. Prog Oceanogr 44:219-243

Daewel U, Schrum C (2013) Simulating long-term dynamics of the coupled North Sea and Baltic Sea ecosystem with ECOSMO II: model description and validation. J Mar Syst 119:30-49

Daewel U, Schrum C, Gupta AK (2015) The predictive potential of early life stage individual-based models (IBMs): an example for Atlantic cod Gadus morhua in the North Sea. Mar Ecol Prog Ser 534:199 219

Emeis K-C, van Beusekom J, Callies U, Ebinghaus R, Kannen A, Kraus G, Kröncke I, Lenhart H, Lorkowski I, Matthias V, Möllmann C, Pätsch J, Scharfe M, Thomas H, Weisse R, Zorita E (2014) The North Sea - a shelf sea in the Anthropocene. J Mar Syst 141:18-33

Gaslikova L, Weisse R (2013) coastDat-2 TRIM-NP-2d Tide-Surge North Sea. World Data Center for Climate (WDCC) at DKRZ. doi:10.1594/WDCC/coastDat-2 TRIM-NP-2d

Geyer B (2014) High-resolution atmospheric reconstruction for Europe 1948-2012: coastDat2. Earth Syst Sci Data 6:147-164. doi:10.5194 lessd-6-147-2014

Giménez L, Dick S (2007) Settlement of shore crab Carcinus maenas on a mesotidal open habitat as a function of transport mechanisms. Mar Ecol Prog Ser 338:159-168

Hurrell JW (1995) Decadal trends in the North Atlantic oscillation: regional temperatures and precipitation. Science 269:676-679

Hurrell JW, Dickson RR (2005) Climate variability over the North Atlantic. In: Stenseth NC, Ottersen G, Hurrell JW, Belgrano A (eds) Marine ecosystems and climate variation. Oxford University Press, Oxford, pp. 15-31

Kapitza H (2008) MOPS - a morphodynamical prediction system on cluster computers. In: Laginha JM, Palma M, Amestoy PR, Dayde M, Mattoso M, Lopez JC (eds) High Performance Computing for Computational Science - VECPAR 2008. June 2008, Toulouse, France. Springer, Heidelberg, pp 63-68

Kauker F, von Storch H (2000) Statistics of "synoptic circulation weather" in the North Sea as derived from a multiannual OGCM simulation. J Phys Oceanogr 30:3039-3049

Kim D, Grant WE, Cairns DM, Bartholdy J (2013) Effects of the North Atlantic Oscillation and wind waves on salt marsh dynamics in the Danish Wadden Sea: a quantitative model as proof of concept. GeoMar Lett 33:253-261. doi:10.1007/s00367-013-0324-4

Kistler R, Kalnay E, Collins W, Saha S, White G, Woollen J, Chelliah M, Ebisuzaki W, Kanamitsu M, Kousky V, van den Dool H, Jenne R, Fiorino M (2001) The NCEP-NCAR 50-year reanalysis: monthly means CD-ROM and documentation. Bull Am Meteorol Soc 82: 247-267

Lamb H (1991) Historic storms of the North Sea, British Isles and Northwest Europe. Cambridge University Press, Cambridge

Lana A, Marmain J, Fernández V, Tintoré J, Orfila A (2016) Wind influence on surface current variability in the Ibiza Channel from HF Radar. Ocean Dyn 66:483-497

Leterme SC, Pingree RD, Skogen MD, Seuront L, Reid PC, Attril MJ (2008) Decadal fluctuations in North Atlantic water inflow in the North Sea between 1958-2003: impacts on temperature and phytoplankton populations. Oceanologia 50:59-72

Lucas J, Koester I, Wichels A, Niggemann J, Dittmar T, Callies U, Wiltshire KH, Gerdts G (2016) Short-term dynamics of North Sea bacterioplankton - dissolved organic matter coherence on molecular level. Front Microbiol 7:321. doi:10.3389/fmicb.2016.00321

Lyard F, Lefevre F, Letellier T, Francis O (2006) Modelling the global ocean tides: modern insights from FES2004. Ocean Dyn 56:394 415

Mathis M, Elizalde A, Mikolajewicz U, Pohlmann T (2015) Variability patterns of the general circulation and sea water temperature in the North Sea. Prog Oceanogr 135:91-112

Oliver H, Rognstad RL, Wethey DS (2015) Using meteorological reanalysis data for multi-decadal hindcasts of larval connectivity in the coastal ocean. Mar Ecol Prog Ser 530:47-62

Parmesan C, Duarte C, Poloczanska E, Richardson AJ, Singer MC (2011) Overstretching attribution. Nature Clim Change 1:2-4

Pätynen A, Kotamäki N, Malve O (2013) Alternative approaches to modelling lake ecosystems. Freshw Rev 6:63-74

Pingree RD, Griffiths DK (1980) Currents driven by a steady uniform wind stress on the shelf seas around the British Isles. Oceanol Acta $3: 227-236$

Planque B (2016) Projecting the future state of marine ecosystems, "la grande illusion"? ICES J Mar Sci 73(2):204-208. doi:10.1093 /icesjms/fsv155

Pohlmann T, Raabe T, Doerffer R, Beddig S, Brockmann U, Dick S, Engel M, Hesse K-J, König P, Mayer B, Moll A, Murphy D, Puls W, Rick H-J, Schmidt-Nia R, Schönfeld W, Sündermann (1999) Combined analysis of field and model data: a case study of the phosphate dynamics in the German Bight in summer 1994. Deutsche Hydrogr Zeitsch 51:331-353

Robins PE, Neill SP, Giménez L, Jenkins SR, Malham SK (2013) Physical and biological controls on larval dispersal and connectivity in a highly energetic shelf sea. Limnol Oceanogr 58:505-524

Scharfe M (2013) Analysis of biological long-term changes based on hydro-climatic parameters in the southern North Sea (Helgoland) (in German). PhD thesis, University of Hamburg, Hamburg 
Schlüter MH, Merico A, Wiltshire KH, Greve W, von Storch H (2008) A statistical analysis of climate variability and ecosystem response in the German Bight. Ocean Dyn 58:169-186

Skogen MD, Moll A (2000) Interannual variability of the North Sea primary production: comparison from two model studies. Cont Shelf Res 20:129-151

Solabarrieta L, Rubio A, Cárdenas M, Castenado S, Esnaola G, Méndez FJ, Medina R, Ferrer L (2015) Probabilistic relationships between wind and surface water circulation patterns in the SE Bay of Biscay. Ocean Dyn 65:1289-1303

Stenseth NC, Ottersen G, Hurrell JW, Belgrano A (eds) (2005) Marine ecosystems and climate variation. Oxford University Press, Oxford

Stockmann K, Callies U, Manly BFJ, Wiltshire KH (2010) Long-term model simulation of environmental conditions to identify externally forced signals in biological time series. In: Müller F, Baessler C, Schubert H, Klotz S (eds) Long-term ecological research - between theory and application. Springer, Heidelberg, pp. 155-162

Sündermann J, Pohlmann T (2011) A brief analysis of North Sea physics. Oceanologia 53:663-689

Van der Veer HW, Ruardij P, Van den Berg AJ, Ridderinkhof H (1998) Impact of interannual variability in hydrodynamic circulation on egg and larval transport of plaice Pleuronectes platessa L. in the southern North Sea. J Sea Res 39:29-40 von Storch H, Zwiers FW (1999) Statistical analysis in climate research. Cambridge University Press, Cambridge

Weisse R, Bisling P, Gaslikova L, Geyer B, Groll N, Hortamani M, Matthias V, Maneke M, Meinke I, Meyer E, Schwichtenberg F, Stempinski F, Wiese F, Wöckner-Kluwe K (2015) Climate services for marine applications in Europe. Earth Perspectives 2:3. doi:10.1186/s40322-015-0029-0

Wiltshire KH, Kraberg A, Bartsch I, Boersma M, Franke H-D, Freund J, Gebühr C, Gerdts G, Stockmann K, Wichels A (2010) Helgoland Roads, North Sea: 45 years of change. Estuar Coasts 33:295-310

Wiltshire KH, Boersma M, Carstens K, Kraberg AC, Peters S, Scharfe M (2015) Control of phytoplankton in a shelf sea: determination of the main drivers based on the Helgoland Roads Time Series. J Sea Res 105:42-52. doi:10.1016/j. seares.2015.06.022

Winter C, Herrling G, Bartholomä A, Capperucci R, Callies U, Heipke C, Schmidt A, Hillebrand H, Reimers C, Bremer P, Weiler R (2014) Scientific concepts for monitoring the ecological state of German coastal seas (in German). Wasser und Abfall 07-08(2014):21-26. doi:10.1365/s35152-0140685-7

Zhao J, Chen X, Hu W, Chen J, Guo M (2011) Dynamics of surface currents over Qingdao coastal waters in August 2008. J Geophys Res 116:C10020. doi:10.1029/2011JC006954 